\title{
Leakage Inductance Calculation for Planar Transformers with a Magnetic Shunt
}

\author{
Zhang, Jun; Ouyang, Ziwei; Duffy, Maeve C.; Andersen, Michael A. E.; Hurley, William G.
}

Published in:

I E E E Transactions on Industry Applications

Link to article, DOI:

10.1109/TIA.2014.2322140

Publication date:

2014

Document Version

Early version, also known as pre-print

Link back to DTU Orbit

Citation (APA):

Zhang, J., Ouyang, Z., Duffy, M. C., Andersen, M. A. E., \& Hurley, W. G. (2014). Leakage Inductance Calculation for Planar Transformers with a Magnetic Shunt. I E E E Transactions on Industry Applications, 50(6), 4107. https://doi.org/10.1109/TIA.2014.2322140

\section{General rights}

Copyright and moral rights for the publications made accessible in the public portal are retained by the authors and/or other copyright owners and it is a condition of accessing publications that users recognise and abide by the legal requirements associated with these rights.

- Users may download and print one copy of any publication from the public portal for the purpose of private study or research.

- You may not further distribute the material or use it for any profit-making activity or commercial gain

- You may freely distribute the URL identifying the publication in the public portal 


\title{
Leakage Inductance Calculation for Planar Transformers with a Magnetic Shunt
}

\author{
Jun Zhang, Student Member, IEEE, Ziwei Ouyang, Member, IEEE, Maeve C. Duffy, Senior Member, IEEE, \\ Michael A. E. Andersen, Member, IEEE, William. G. Hurley, Fellow, IEEE
}

\begin{abstract}
The magnetic shunt is generally inserted in a planar transformer to increase the leakage inductance which can be utilized as the series inductor in resonant circuits such as the LLC resonant converter. This paper presents a calculation methodology for the leakage inductance of the transformer with a magnetic shunt by means of the stored magnetic energy in the primary and secondary sides of the transformer using the magnetomotive force (MMF) variation method, as well as the stored energy in the shunt based on the reluctance model. The detailed calculation method is described. Both the FEA simulation and the experimental results have proven the validity of the proposed calculation method for leakage inductance.
\end{abstract}

Index Terms-Leakage inductance, magetomotive force (MMF), magnetic shunt, planar transformer, resonant converter, reluctance model

\section{NOMENCLATURE}

$A_{c} \quad$ Effective cross sectional area of the core

$b_{c} \quad$ Width of the outer leg of the core

$b_{w} \quad$ Width of the core window

$E_{\text {core }} \quad$ Energy stored in the core

$E_{\text {pri }} \quad$ Energy stored in the primary side

$E_{\text {sec }} \quad$ Energy stored in the secondary side

$E_{\text {shunt }} \quad$ Energy stored in the magnetic shunt

$f_{p} \quad$ MMF in each layer of the primary winding

$f_{s} \quad$ MMF in each layer of the secondary winding

$h \quad$ Thickness of the magnetic shunt

$h_{p} \quad$ Thickness of each layer in the primary winding

$h_{\Delta p} \quad$ Separation distance of primary layers

$h_{s} \quad$ Thickness of each layer in the secondary winding

$h_{\Delta s} \quad$ Separation distance of primary layers

$I_{p} \quad$ Current across the primary winding

$k_{p} \quad$ Turns per layer in the primary side

Manuscript received October 3, 2013; revised January 13, 2014; accepted April 10, 2014.Paper 2013-PEDCC-712.R1, presented at the 2013 IEEE Energy Conversion Congress and Exposition, Denver, CO, USA, September 15-19, and approved for publication in the IEEE TRANSACTIONS ON INDUSRY APPLICATIONS by the Power Electronic Devices and Components Committee of the IEEE Industry Applications Society. This work was supported by the Chinese Scholarship Council (CSC).

Jun Zhang, Maeve C. Duffy and William G. Hurley are with the Power Electronics Research Centre, National University of Ireland, Galway, Ireland (e-mail: junzhang.inbox@gmail.com; maeve.duffy@nuigalway.ie ; ger.hurley@nuigalway.ie ).

Ziwei Ouyang and Michael A.E. Andersen are with the Department of Electrical Engineering, Technical University of Denmark, Kongens, Lyngby DK-2800, Denmark (e-mail: zo@elektro.dtu.dk; ma@elektro.dtu.dk )

Digital Object Identifier

$\begin{array}{ll}k_{s} & \text { Turns per layer in the secondary side } \\ l_{c} & \text { Effective length of the core } \\ l_{w} & \text { Depth of the magnetic core } \\ N_{p} & \text { Number of primary layers } \\ N_{s} & \text { Number of secondary layers } \\ \mathrm{P}(n) & \text { The } n \text {th layer of the primary winding } \\ \mathrm{S}(n) & \text { The } n \text {th layer of the secondary winding } \\ x & \text { Distance from the top winding (see Fig. 3) } \\ \mu_{0} & \text { Magnetic permeability of free space } \\ \mu_{r} & \text { Relative permeability of the core } \\ \mu_{s} & \text { Relative permeability of the magnetic shunt }\end{array}$

\section{INTRODUCTION}

The correct prediction of leakage inductance in transformers is critical for LLC resonant converters because a well-matched resonant frequency is required [1], [2]. Traditional LLC converters use a wire-wound transformer and an additional magnetic component for the resonant inductor, resulting in a significant increase in the overall size of the converter. Nowadays, many efforts involve integrated magnetics and planar magnetics for LLC converters [3]-[6]. Inserting a magnetic shunt into the transformer winding layers is a common method to increase the leakage inductance, as shown in Fig. 1.

Many publications have made excellent analysis and calculations for leakage inductance in conventional and planar transformers [7]-[12]. However, none of published literature has predicted an accurate leakage inductance for planar transformers with an inserted magnetic shunt. This paper focuses on the leakage inductance calculation in planar transformers based on magnetomotive force (MMF) analysis and leakage energy distribution along the conductors,

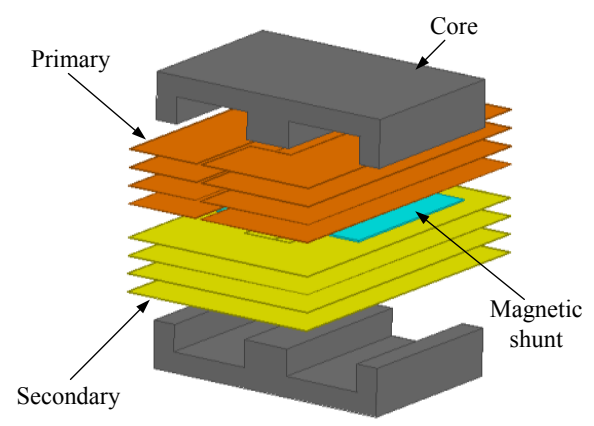

Fig. 1. The planar transformer with magnetic shunt 
insulators and magnetic shunt. Section III gives a detailed analysis on the leakage inductance and proposes a formula to calculate the leakage inductance with a magnetic shunt consideration. Section IV presents a comparison of the calculations, FEA simulation results and the experimental results. Several planar transformer prototypes with different magnetic shunts have been built to verify the proposed calculation method. At last, conclusions are reached in section $\mathrm{V}$.

\section{LEAKAGE INDUCTANCE CALCULATION METHOD}

\section{A. Basic Definition of Leakage Inductance}

In a typical transformer, the flux generated by ac current excitation in the primary winding follows the magnetic circuit and link with the secondary winding. Some flux will leak from the core and return to the air, winding layers and insulator layers without linking the secondary windings. The partial coupling of the flux results in leakage inductance. Fig. 2 shows the leakage flux paths and the magnetomotive force (MMF) variation in the transformer.

Within the winding area the leakage flux is approximately parallel to the winding interface. The leakage inductance referred to the primary side can be calculated by the energy stored in the magnetic field,

$$
E=\frac{1}{2} \int_{V} B \cdot H d V=\frac{1}{2} \cdot L_{k} \cdot I_{p}^{2}
$$

where $V$ is the total effective volume and $I_{p}$ is the current in the primary winding.

\section{B. Leakage Inductance Calculation}

A description for the leakage inductance calculation based on the energy methodology can be found in [13]. This paper describes how the insertion of a magnetic shunt offers a more consistent and definable leakage inductance, and proposes the calculation methodology based on the MMF and the reluctance model. Fig. 3 presents the simplified analytical scheme of MMF distribution along the winding layers for the

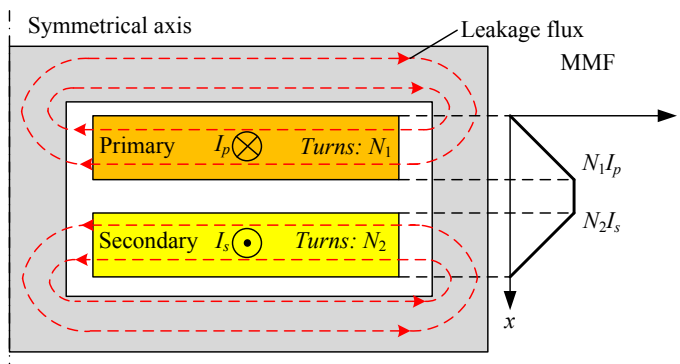

Fig. 2. The leakage flux paths and MMF curve

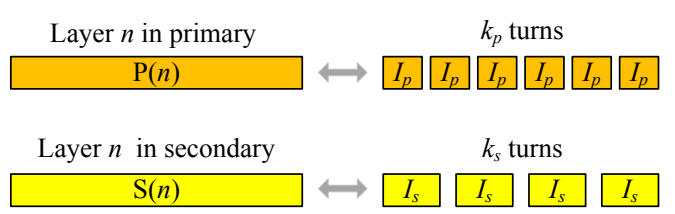

Fig. 4. The schematic diagram for the number of turns in each layer simple case of a planar transformer with magnetic shunt inserted in the middle of the core window. The numbers of layers in the primary and secondary are labeled as $N_{p}$ and $N_{s}$, respectively.

In planar transformers, the windings are generally implemented by PCB or copper foil. The number of turns in each layer of the primary and secondary side is $k_{p}$ and $k_{s}$, respectively and corresponding currents are $I_{p}$ and $I_{s}$, respectively as shown in Fig. 4. The MMF along the flux path which includes the layer depends on the number of ampere turns linked by the path. Thus, the MMF in each layer of the primary and secondary windings is given as:

$$
f_{p}=k_{p} \cdot I_{p}, \quad f_{s}=k_{s} \cdot I_{s}
$$

In order to obtain the leakage inductance of the presented planar transformer, the total magnetic energy stored in the window area including the energy in the primary side $E_{\text {pri }}$, the secondary side $E_{\text {sec }}$ and the magnetic shunt $E_{\text {shunt }}$ must be analyzed and calculated. Based on Fig. 3, the magnetic field intensity in the shunt inside the core widow can be calculated by assuming the MMF in it is $N_{p} f_{p}$ and the field intensity in the shunt across the core legs is 0 . On the other hand, the reluctance model can be applied to obtain the magnetic field intensity in the shunt with the reluctance of the windings ignored because the shunt leakage energy may dominate the total leakage energy. Two calculation methods will be compared.

1) Energy stored in the primary side and the secondary windings: Based on the analysis of the magnetic field intensity $H$ in the primary side, the stored energy in the primary $E_{\text {pri }}$ can be obtained. Fig. 5 shows the MMF in vicinity of layer $n$ in the primary where $n$ can be accumulated from 1 to $N_{p}$. The relation between the magnetic field intensity $H$ and the geometric position $x$ is shown as (3).

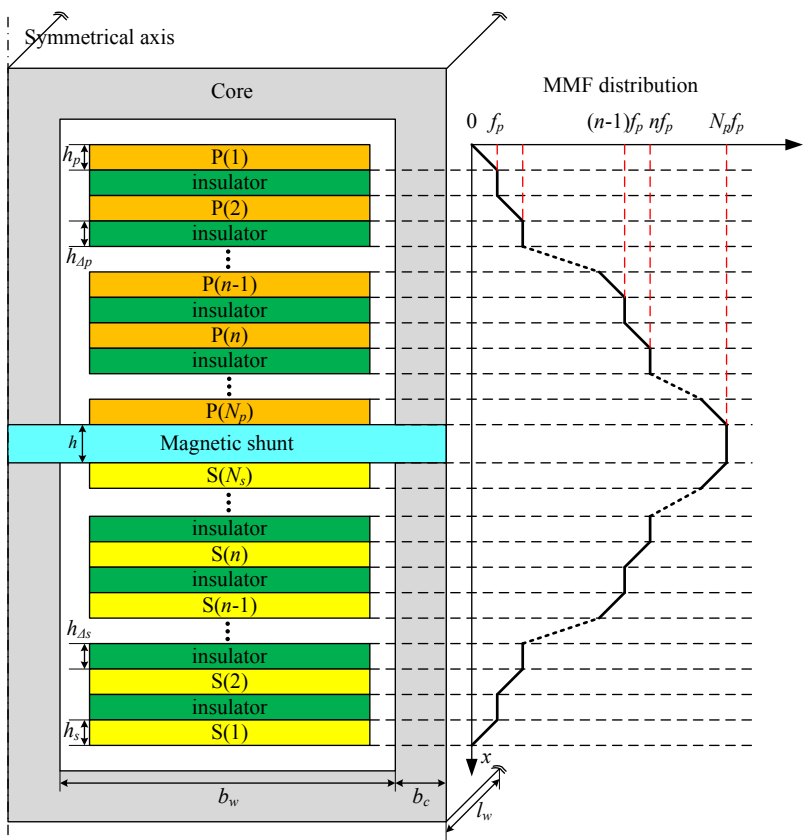

Fig. 3. The simplified analytical scheme of MMF distribution for the planar transformer with magnetic shunt 


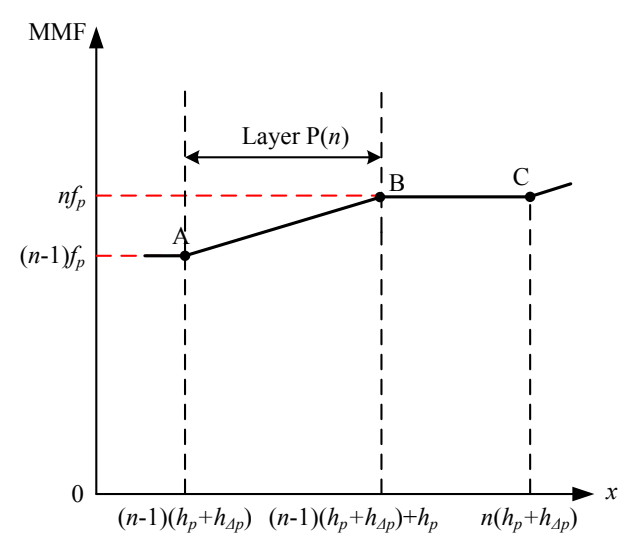

Fig. 5. The distribution and calculation of MMF

$$
H(x)=\left\{\begin{array}{l}
\frac{(n-1) f_{p}}{b_{w}}+\frac{f_{p}}{h_{p} b_{w}}\left[x-(n-1)\left(h_{p}+h_{\Delta p}\right)\right] \\
\text { when }(n-1)\left(h_{p}+h_{\Delta p}\right)<x \leq(n-1)\left(h_{p}+h_{\Delta p}\right)+h_{p} \\
\frac{n f_{p}}{b_{w}} \\
\text { when }(n-1)\left(h_{p}+h_{\Delta p}\right)+h_{p}<x \leq n\left(h_{p}+h_{\Delta p}\right)
\end{array}\right.
$$

The energy $E_{\text {pri }}$ can be calculated by (1) and written as (4).

$$
E_{\mathrm{pri}}=2 \cdot \frac{1}{2} \mu_{0} l_{w} b_{w}\left[\begin{array}{l}
\sum_{n=1}^{N_{p}} \int_{(n-1)\left(h_{p}+h_{\Delta p}\right)}^{(n-1)\left(h_{p}+h_{\Delta p}\right)+h_{p}} H^{2}(x) d x \\
+\sum_{n=1}^{N_{p}-1} \int_{(n-1)\left(h_{p}+h_{\Delta p}\right)+h_{p}}^{n\left(h_{p}+h_{\Delta p}\right)} H^{2}(x) d x
\end{array}\right]
$$

In (4), $l_{w}$ is the depth of the magnetic core or the shunt, see Fig. 3. Combining (3) and (4), it can be obtained

$$
E_{\mathrm{pri}}=\frac{1}{6} \mu_{0} \frac{l_{w}}{b_{w}} k_{p}^{2}\left[2 h_{p} N_{p}^{3}+h_{\Delta p}\left(2 N_{p}^{3}-3 N_{p}^{2}+N_{p}\right)\right] I_{p}^{2}
$$

Similarly,

$$
E_{\mathrm{sec}}=\frac{1}{6} \mu_{0} \frac{l_{w}}{b_{w}} k_{s}^{2}\left[2 h_{s} N_{s}^{3}+h_{\Delta s}\left(2 N_{s}^{3}-3 N_{s}^{2}+N_{s}\right)\right] I_{s}^{2}
$$

2) Energy stored in the magnetic shunt: First method, the MMF in the magnetic shunt is assumed to be $N_{p} f_{p}$ and then,

$$
H_{s}=\frac{N_{p} f_{p}}{b_{w}}
$$

The energy stored in the total magnetic shunt is

$$
E_{\text {shunt }}=\mu_{0} \mu_{s} \frac{h l_{w}}{b_{w}} k_{p}^{2} N_{p}^{2} I_{p}^{2}
$$

Thus, the leakage inductance based on this method is

$$
L_{k}=\frac{\mu_{0} l_{w} k_{p}^{2} N_{p}^{2}}{3 b_{w}}\left\{\sum_{i=p, s}\left[2\left(h_{i}+h_{\Delta i}\right) N_{i}-3 h_{\Delta i}+\frac{h_{\Delta i}}{N_{i}}\right]+6 \mu_{s} h\right\}
$$

The secondary method is based on the reluctance model of the transformer because the main magnetic flux path is changed with the shunt inserted as shown in Fig. 3. The MMF in the magnetic shunt should not be assumed as $N_{p} f_{p}$ under some conditions. In general, the permeability of magnetic

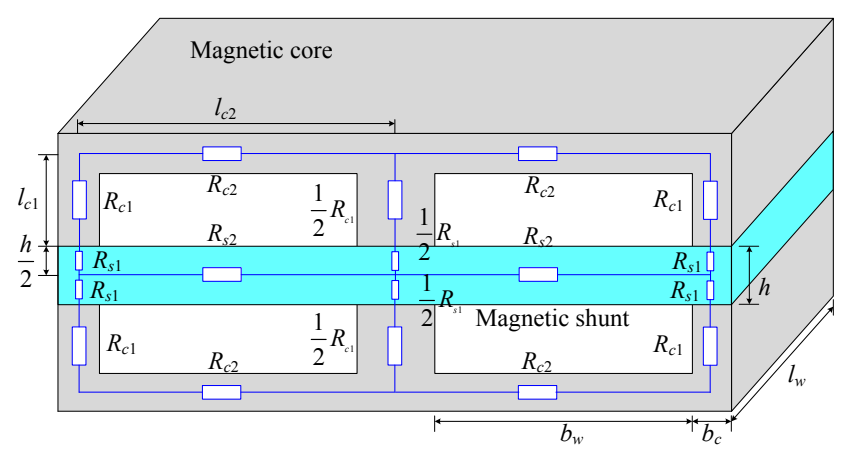

Fig. 6. Reluctances distributed in the transformer

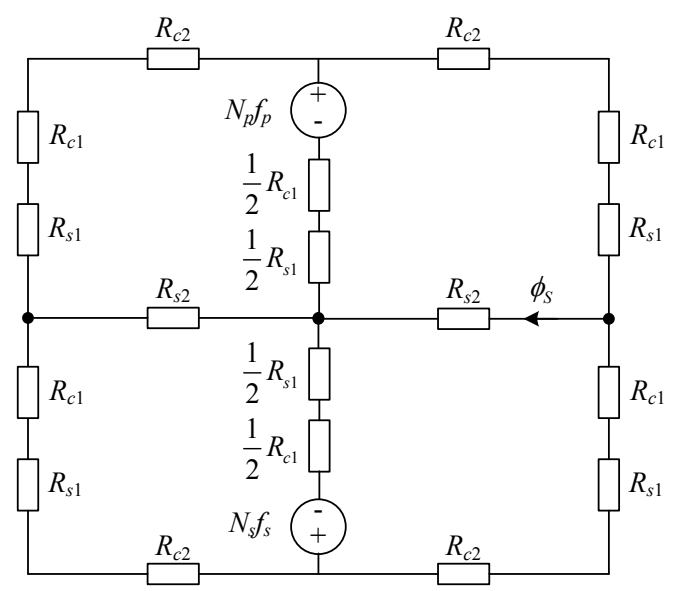

Fig. 7. The reluctance model of the transformer

shunt is substantially higher than the permeability of air, the energy stored in the magnetic shunt dominates the total leakage energy. Fig. 6 shows the reluctance model of leakage inductance calculation in the planar transformer with the inserted magnetic shunt with the reluctance of windings ignored. The reluctance of the magnetic core $R_{c 1}$ and $R_{c 2}$, the reluctance of the shunt $R_{s 1}$ and $R_{s 2}$ can be calculated by

$$
\begin{aligned}
& R_{c 1}+\frac{1}{2} R_{c 2}=\frac{l_{c}}{2 \mu_{0} \mu_{r} A_{c}} \\
& R_{s 1}=\frac{h}{2 \mu_{0} \mu_{s} b_{c} l_{w}}, \quad R_{s 2}=\frac{b_{w}}{\mu_{0} \mu_{s} h l_{w}}
\end{aligned}
$$

where $\mu_{r}, \mu_{s}$ are the relative permeability of the core and shunt respectively, $A_{c}$ is the effective cross sectional area of the core, $l_{c}$ is the effective length of the EE core and other parameters are labeled in Fig.6. Fig. 7 gives the reluctance model of the planar transformer.

From the magnetic reluctance model, the magnetic flux in the shunt inside the window is

$$
\phi_{S}=\frac{N_{p} f_{p}}{R_{c 1}+\frac{1}{2} R_{c 2}+R_{s 1}+R_{s 2}}
$$

If $a$ was defined as

$$
a=\frac{R_{s 2}}{R_{c 1}+\frac{1}{2} R_{c 2}+R_{s 1}+R_{s 2}}
$$


The magnetic field intensity of the shunt inside the window $H_{s w}$ is

$$
H_{s w}=\frac{1}{b_{w}} a N_{p} f_{p}
$$

The magnetic field intensity of the shunt inside the core $H_{s c}$ is

$$
H_{s c}=\frac{R_{s 1}}{h R_{s 2}} a N_{p} f_{p}
$$

The magnetic field intensity of the core $H_{c o r e}$ is

$$
H_{\text {core }}=\frac{R_{c 1}+\frac{1}{2} R_{c 2}}{2 l_{c} R_{s 2}} a N_{p} f_{p}
$$

The total leakage energy stored in the magnetic shunt $E_{\text {shunt }}$ is

$$
E_{\text {shunt }}=\mu_{0} \mu_{s}\left(\frac{h l_{w}}{b_{w}}+\frac{2 b_{c} l_{w} R_{s 1}^{2}}{h R_{s 2}^{2}}\right) a^{2} k_{p}^{2} N_{p}^{2} I_{p}^{2}
$$

The energy stored in the magnetic core $E_{\text {core }}$ is

$$
E_{\text {core }}=\mu_{0} \mu_{r} \frac{A_{c}}{8 l_{c} R_{s 2}^{2}}\left(R_{c 1}+\frac{1}{2} R_{c 2}\right)^{2} a^{2} k_{p}^{2} N_{p}^{2} I_{p}^{2}
$$

From the balance of the MMF in the primary and the secondary windings,

$$
N_{p} k_{p} I_{p}=N_{s} k_{s} I_{s}
$$

Combing (1), (5), (6), (16), (17) and (18), the leakage inductance referred to the primary of the planar transformer with magnetic shunt can be expressed by (19) shown at the bottom of the page.

The two calculation methods will be compared and evaluated by the simulation and experimental results.

\section{METHOdS EVALUATION AND EXPERIMENTAL VERIFICATION}

The leakage calculations demonstrate that the relative permeability and the thickness of the magnetic shunt are significant in terms of the leakage inductance. The magnetic shunt should be selected carefully in order to achieve the design. 2D Finite Element Analysis (FEA) simulations for the ELP 43/10/28 core with different shunts have been performed. The detailed specifications of the planar transformer are presented in Table I. Fig. 8 shows the simulation results of the magnetic field intensity in the core window corresponding to the calculations by (3). The magnetic field intensity is much higher in the shunt than elsewhere, which means the leakage energy is mainly stored in the magnetic shunt.

In order to verify the proposed calculation methodology and compare the presented two calculation methods, magnetic shunts with different relative permeability were studied: (1) $\mu_{s}=10$; (2) $\mu_{s}=40$; (3) $\mu_{s}=100$; (4) $\mu_{s}=150$; (5) $\mu_{s}=200$. The thickness of the shunt $\mathrm{h}$ is varied from $0.1 \mathrm{~mm}$ to $2 \mathrm{~mm}$. The two methods to calculate the leakage inductance have been
TABLE I

SPECIFICATIONS OF THE PLANAR TRANSFORMER FOR SIMULATIONS

\begin{tabular}{ll}
\hline Core material & $\mathrm{N} 87$ \\
\hline Primary layers $N_{p}$ & 4 \\
\hline Turns per layer in primary $k_{p}$ & 1 \\
\hline Thickness of each layer in primary $h_{p}$ & $0.15 \mathrm{~mm}$ \\
\hline Separation in primary $h_{\Delta p}$ & $0.4 \mathrm{~mm}$ \\
\hline Secondary layers $N_{s}$ & 4 \\
\hline Turns per layer in secondary $k_{s}$ & 1 \\
\hline Thickness of each layer in secondary $h_{s}$ & $0.15 \mathrm{~mm}$ \\
\hline Separation in secondary $h_{\Delta s}$ & $0.4 \mathrm{~mm}$ \\
\hline
\end{tabular}

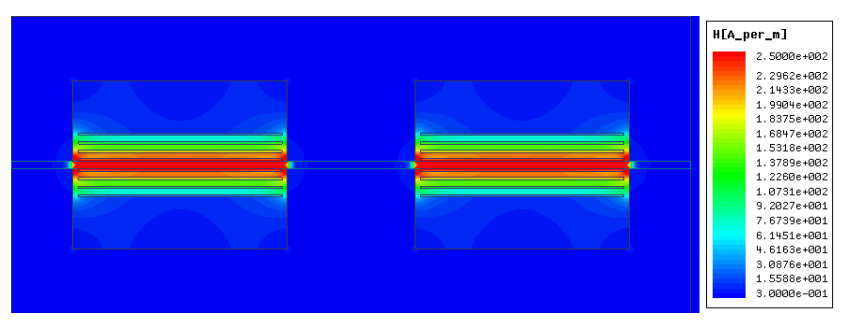

Fig. 8. Simulation results of the magnetic intensity with $\mu_{r}=10, h=0.4 \mathrm{~mm}$

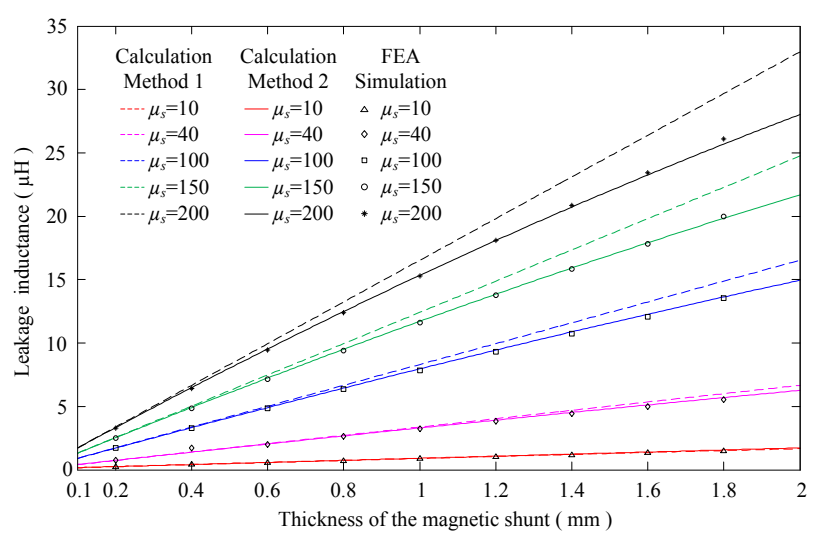

Fig. 9. Comparison of the calculation and FEA simulation results for the stored energy in the magnetic shunt

compared with the simulation results as shown in Fig. 9. It is indicated that the calculation method of the leakage inductance presented as (19) with the reluctance model applied is more accurate.

Further experiments were carried out to verify the proposed calculation method. Four kinds of the PCB windings have been built; the magnetic core for the planar transformer is ELP 43/10/28. Two PCB windings are shown in Fig. 10. The thickness of the insulator between two windings and the number of layers in PCB1 and PCB2 are different. The insulator thicknesses in PCB1 and PCB2 are $0.4 \mathrm{~mm}$ and 1.5 $\mathrm{mm}$ while numbers of turns are 4 and 2 , respectively. Three transformers have been built and the parameters are shown in Table. II Thicknesses of shunts used in the planar transformer

$$
L_{k}=\frac{1}{3} \mu_{0} k_{p}^{2} N_{p}^{2} \frac{l_{w}}{b_{w}}\left\{\sum_{i=p, s}\left[2\left(h_{i}+h_{\Delta i}\right) N_{i}-3 h_{\Delta i}+\frac{h_{\Delta i}}{N_{i}}\right]+6 \mu_{s}\left(h+\frac{2 b_{c} b_{w} R_{s 1}^{2}}{h R_{s 2}^{2}}\right) a^{2}+\frac{3}{4} \mu_{r} \frac{b_{w} A_{c}}{l_{w} l_{c} R_{s 2}^{2}}\left(R_{c 1}+\frac{1}{2} R_{c 2}\right)^{2} a^{2}\right\}
$$


TABLE II

SPECIFICATIONS OF DIFFERENT PLANAR TRANSFORMERS FOR EXPERIMENTS

\begin{tabular}{llll}
\hline Parameters & Trans. 1 & Trans. 2 & Trans. 3 \\
\hline Primary & PCB1 & PCB2 & PCB2 \\
\hline Secondary & PCB1 & PCB1 & PCB2 \\
\hline$N_{p}$ & 4 & 2 & 2 \\
\hline$N_{s}$ & 4 & 4 & 2 \\
\hline$k_{p}$ & 1 & 1 & 1 \\
\hline$k_{s}$ & 1 & 1 & 1 \\
\hline$h_{p}$ & $0.15 \mathrm{~mm}$ & $0.15 \mathrm{~mm}$ & $0.15 \mathrm{~mm}$ \\
\hline$h_{s}$ & $0.15 \mathrm{~mm}$ & $0.15 \mathrm{~mm}$ & $0.15 \mathrm{~mm}$ \\
\hline$h_{\Delta p}$ & $0.4 \mathrm{~mm}$ & $1.5 \mathrm{~mm}$ & $1.5 \mathrm{~mm}$ \\
\hline$h_{\Delta s}$ & $0.4 \mathrm{~mm}$ & $0.4 \mathrm{~mm}$ & $1.5 \mathrm{~mm}$ \\
\hline
\end{tabular}

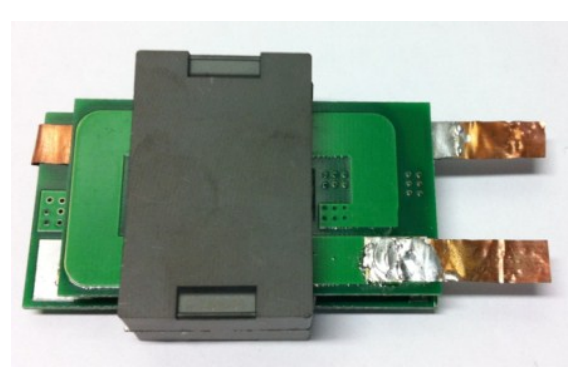

Fig. 11. The planar transformer with magnetic shunt (Trans. 1)

are $0.5 \mathrm{~mm}$ and $1 \mathrm{~mm}$ with the relative permeability of 30 . Finally, six planar transformers have been tested and Trans. 1 is shown in Fig. 11.

The leakage inductance of each planar transformer has been tested, with an Agilent 4395A impedance analyzer, with the secondary winding of the transformer shorted. The values of the leakage inductance were measured at $100 \mathrm{kHz}$ and the average value for 16 test results was selected as the measured inductance. Comparisons of the calculation and experimental results for each transformer are shown in Fig. 12. Fig. 12 (a) and (b) show the calculation and experimental results for the three tested transformers with the thickness of the magnetic shunt $0.5 \mathrm{~mm}$ and $1 \mathrm{~mm}$, respectively. The experimental results indicate that the proposed calculation method based on the reluctance model for the leakage inductance of the planar transformer with a magnetic shunt is valid.

\section{V.CONCLUSIONS}

This paper presents a new methodology for the calculation of leakage inductance in the planar transformers with a magnetic shunt based on the stored magnetic energy in the primary and secondary side of the transformer as well as the stored energy in the shunt. The reluctance model is utilized to obtain the magnetic field density in the magnetic shunt and proved to be a better calculation method to obtain the leakage inductance. The proposed model is available for the selection of the magnetic shunt in applications where the leakage inductance can be applied as a series inductor in the circuit, such as the resonant inductor in the LLC resonant converter. The FEA simulations have been carried out and results

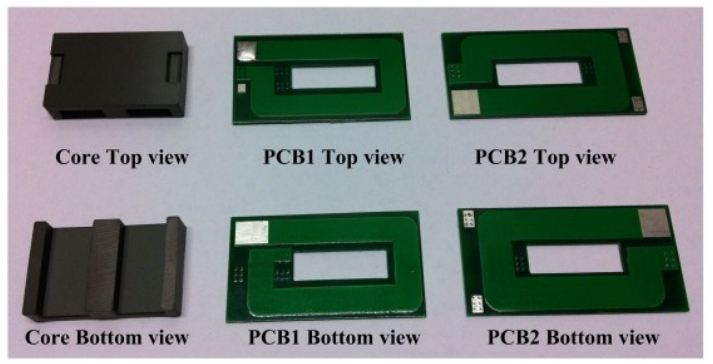

Fig. 10. PCB windings and the planar magnetic core

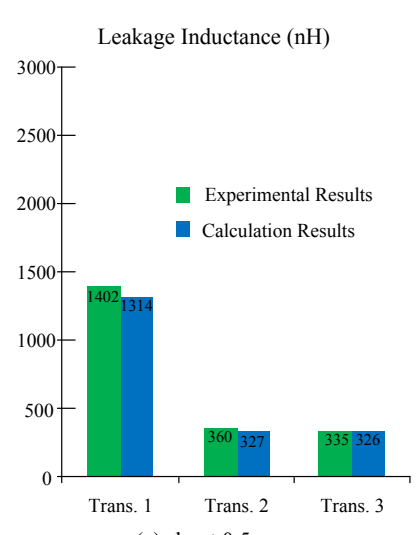

(a) shunt $0.5 \mathrm{~mm}$

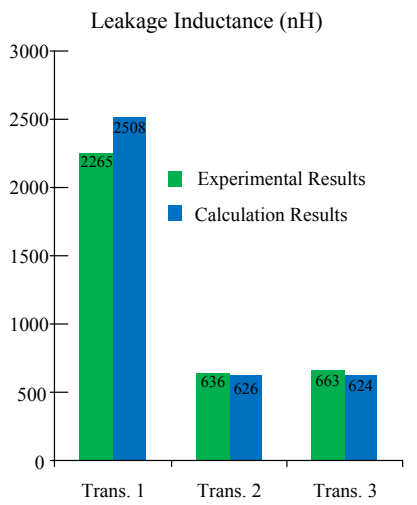

(b) shunt $1 \mathrm{~mm}$
Fig. 12. Comparisons of the calculations and experimental results of the leakage inductance

calculated by the proposed equation correspond well with the simulation results. Several prototypes of the planar transformer have been built and the measured leakage inductance agrees with the theoretical computation.

\section{ACKNOWLEDGEMENT}

The author, Jun Zhang, would like to acknowledge the support of the Chinese Scholarship Council (CSC).

\section{REFERENCES}

[1] D. Fu, F. C. Lee and W. Shuo, "Investigation on transformer design of high frequency high efficiency dc-dc converters," in Proc. 2010 IEEE Applied Power Electronics Conference and Exposition (APEC), pp. 940947.

[2] J. Jee-Hoon, "Bifilar winding of a center-tapped transformer including integrated resonant inductance for LLC resonant converters," IEEE Trans. Power Electronics, vol.28, pp. 615-620, 2013.

[3] K. Duk-You, K. Chong-Eun and M. Gun-Woo, "High-efficiency slim adapter with low-profile transformer structure," IEEE Trans. Industrial Electronics, vol.59, pp. 3445-3449, 2012.

[4] D. Fu and S. Wang, "Novel concepts for high frequency high efficiency transformer design," in Proc. 2011 IEEE Energy Conversion Congress and Exposition (ECCE), pp. 3800-3807.

[5] S. R. Cove, M. Ordonez, F. Luchino and J. E. Quaicoe, "Integrated magnetic design of small planar transformers for LLC resonant converters," in Proc. 2011 IEEE Energy Conversion Congress and Exposition (ECCE), pp. 1839-1844.

[6] L. Wenduo and J. D. van Wyk, "Design of integrated LLCT module for LLC resonant converter," in Proc. 2005 IEEE Applied Power Electronics Conference and Exposition (APEC), pp. 362-368.

[7] W. G. Hurley and D. J. Wilcox, "Calculation of leakage inductance in transformer windings," IEEE Trans. Power Electronics, vol.9, pp. 121126, 1994. 
[8] V. Leonavièius, M. Duffy, S. C. Ó Mathúna, "Planar controlled-leakageinductance transformer with magnetic shunt - application in resonant AC/DC converter", Proceedings of EPE - PEMC '04, Riga, Latvia, September 2004.

[9] J. Biela and J. W. Kolar, "Electromagnetic integration of high power resonant circuits comprising high leakage inductance transformers," in Proc. 2004 IEEE Power Electronics Specialists Conference, pp. 45374545.

[10] Z. Ouyang, Z. Zhang, O. C. Thomsen and M. A. E. Andersen, "Planarintegrated magnetics (PIM) module in hybrid bidirectional DC-DC converter for fuel cell application," IEEE Trans. Power Electronics, vol.26, pp. 3254-3264, 2011.

[11] S. R. Cove, M. Ordonez, F. Luchino, and J. E. Quaicoe, "Applying Response Surface Methodology to Small Planar Transformer Winding Design," IEEE Trans. Industrial Electronics, vol. 60, pp. 483-493, 2013.

[12] Z. Ouyang, O. C. Thomsen and M. A. E. Andersen, "Optimal design and tradeoff analysis of planar transformer in high-power dc-dc converters," IEEE Trans. on Industrial Electronics, vol.59, no.7, pp.2800-2810, July 2012.

[13] Z. Ouyang, O. C. Thomsen, and M. A. E. Andersen, "The analysis and comparison of leakage inductance in different winding arrangements for planar transformer," in Proc. IEEE PEDS, pp. 1143-1148, Taipei, Taiwan, Nov., 2009.

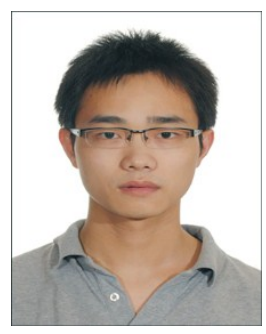

Jun Zhang (S'13) was born in Anhui, China, in 1987. He received the B.S. degree and M.S. degree in electrical engineering, from the Department of Electrical Engineering, Zhejiang University, Hangzhou, China, in 2008 and 2011, respectively. He is currently working toward the Ph.D. degree in the Power Electronics Research Centre, NUI Galway, Galway, Ireland.

His research interests include high frequency resonant converter and planar magnetics.

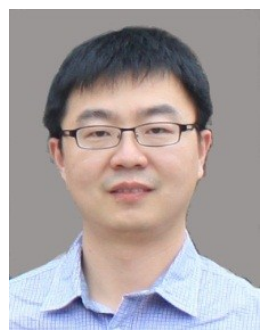

Ziwei Ouyang (S'07, M'11) received the B.S degree in electrical engineering from the Naval University of Engineering, Wuhan, China, in 2004, the M.S degree from the Tianjin University of Technology, Tianjin, China, in 2007, and the Ph.D degree from the Technical University of Denmark (DTU), Denmark, in 2011. He worked as a Postdoctoral Researcher at DTU from 2011 to 2013 and is currently assistant professor in the Department of Electrical Engineering at DTU.

His current research interests include advanced magnetics design, modelling and integration in switch mode power supplies, dc/dc converters, and digital control in high-power reversible converters. He is the holder of three US/EP/PCT patents. He is member of the IEEE PELS, IES and Magnetics societies.

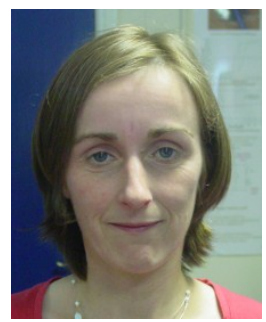

Maeve C. Duffy (SM'09) graduated with a $\mathrm{PhD}$ in Electronic Engineering from the National University of Ireland, Galway in 1997. From 1997 - 2001, she was a Research Assistant with PEI Technologies at the NMRC (Tyndall) in Cork, Ireland, where her research focused on planar magnetics for power electronic applications. Since then, she has been a Lecturer in Electrical \& Electronic Engineering at NUI Galway.

Her current research interests are in magnetic component modelling and design for microprocessor loads, energy harvesting and wireless power systems. She was an elected member of the AdCom of the IEEE Power Electronics Society from 2006 to 2008.

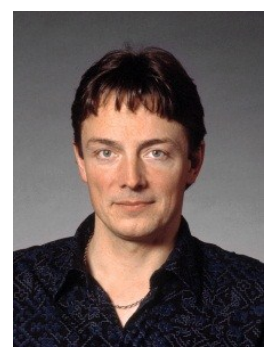

Michael A. E. Andersen (M'88) received the M.Sc.E.E. and Ph.D. degrees in power electronics from the Technical University of Denmark, Kongens Lyngby, Denmark, in 1987 and 1990, respectively. $\mathrm{He}$ is currently a Professor of power electronics at the Technical University of Denmark. Since 2009, he has been Deputy Head of Department at the Department of Electrical Engineering. He is the author or coauthor of more than 200 publications.

His research interests include switch-mode power supplies, piezoelectric transformers, power factor correction, and switch-mode audio power amplifiers.

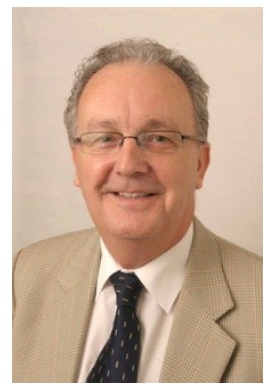

William Gerard Hurley (M'77, SM'90, F'07) received the B.E. degree from University College Cork, the M.S. degree from M.I.T., and the PhD degree from the National University of Ireland, Galway.

He worked in Canada from 1977 to 1983 for Honeywell and Ontario Hydro. He is currently Professor of Electrical Engineering at the National University of Ireland, Galway. Research interests include High Frequency Magnetics, Power Quality, and Renewable Energy systems. He received the IEEE Power Electronics Society Middlebrook Technical Achievement Award for 2013. He is a Distinguished Lecturer of the IEEE Power Electronics Society for 2014-15. He has co-authored several papers and a textbook on magnetics.

Prof. Hurley is a Fellow of the IEEE. He was General Chair of the IEEE Power Electronics Specialists Conference in 2000. 